\title{
Esboço do programa científico de uma sociologia psicológica*
}

\author{
Bernard Lahire*
}

\begin{abstract}
Resumo
0 autor esboça neste artigo o programa científico de uma sociologia psicológica. Realizar uma análise sociológica na escala do indivíduo socializado é, entre outros, estudar muito precisamente a constituição das disposições sociais, as formas de interiorização e de exteriorização dos hábitos, os efeitos mentais e identitários da incorporação de disposições heterogêneas e, às vezes, contraditórias... Essa sociologia psicológica, que responde a uma dupla necessidade (histórica e científica), não é contrária aos métodos estatísticos e generalizantes, mas pretende somente dotar a sociologia de ferramentas (conceituais e metodológicas) adequadas à apreensão das marcas mais singulares do social.
\end{abstract}

\section{Existem objetos mais sociais que outros?}

Onde e como apreender o social? Eis aqui uma questão que, no fundo, nunca cessou de se colocar aos pesquisadores em ciências sociais, e que deu lugar a uma inacreditável diversidade de respostas conforme as diferentes tradições sociológicas. As ciências do mundo social teriam, aliás, objetos prediletos no mundo? Uma epistemologia realista levaria a pensar que certos objetos do mundo seriam "sociais", enquanto outros não (ou menos). Assim, os movimentos coletivos, os grupos, as classes, as instituições seriam "por evidência" objetos para as ciências sociais, enquanto o comportamento de um indivíduo singular, as neuroses, as depressões, os sonhos, as emoções, os objetos técnicos que nos rodeiam etc. seriam objetos de estudo para psicossociológicos, psicólogos, psicanalistas, médicos, engenheiros, ergonômicos etc. Ora, sabese que, em sua prática científica efetiva, os pesquisadores estão em vias de fazer explodir em faíscas essas fronteiras realistas. De fato, como afirmou enfaticamente Saussure, é o ponto de vista que cria o objeto e não o objeto que obedeceria/esperaria docilmente no real (na realidade) o ponto de vista científico que viria revelá-lo.
É por não excluir a priori nenhum assunto de seu campo de estudo que as ciências sociais podem obter um progresso rumo à maior autonomia científica. Assim como a literatura "mais pura" que, por manifestar a ruptura com as demandas externas, afirma o primado do mundo da representação sobre o objeto representado, as ciências sociais devem mostrar que não há nenhum limite empírico àquilo que elas são suscetíveis de estudar, isto é, que não há objetos mais sociológicos, mais antropológicos ou mais históricos que outros, mas que o essencial reside no modo científico (sociológico, antropológico, histórico etc.) de tratamento do assunto'.

No entanto, essas extensões cognitivas que uma disciplina científica é suscetível de constituir em objetos de estudo não são jamais simples de operar. É, dessa forma, impossível,

* Título original: Cahiers Internationaux de Sociologie, v. CVI, p. 29-55, 1999. Tradução de Felipe de Souza Tarábola, mestrando em Psicologia e Educação na Faculdade de Educação da USP.

**Professor de Sociologia da Ecole Normale Supérieure Lettres et Sciences Humaines. Diretor do Grupo de Pesquisa sobre Socialização (UMR 5040 CNRS). 1. Por exemplo, a sociologia progrediria de modo diretamente proporcional ao fato de não se contentar em se entricheirar na periferia dos lugares clássicos da psicologia. Não é questão de estudar somente a percepção social e histórica da doença mental ou da trajetória socioinstitucional de uma doença mental, mas sim a produção social da própria doença. E 0 mesmo se aplica ao sonho, ao estresse, à depressão... 
na maioria dos casos, aplicar mecanicamente a novos temas ou assuntos os conceitos ou os métodos antigamente aprovados. É nisso que os temas de estudo resistem muito mais além daquilo que a idéia de uma epistemologia nominalista nos permitiria pensar. A aplicação de antigos esquemas interpretativos sobre novas realidades pode simplesmente contribuir com o reforço da crença na incapacidade intrínseca da disciplina em estudar essas realidades. Um outro risco reside na utilização pela sociologia, sob a forma de uma importação fraudulenta e, por conseqüência, não controlada, de esquemas interpretativos oriundos de tradições disciplinares alheias a seu próprio desenvolvimento científico.

\section{O social individualizado}

A dificuldade de compreender o social sob sua forma individualizada ocorre, assim, devido a dois riscos permanentes: primeiramente, o fato de crer poder estudar o novo (tema de estudo), reciclando simplesmente o antigo (conceitos e métodos); em um segundo momento, o fato de supor poder alcançar esses fins científicos fazendo uma bricolagem entre uma sociologia disso (de origem sociológica) e daquilo (de origem psicológica).

Ao se colocar voluntariamente de lado o segundo tipo de risco (que já deu lugar, por exemplo, às infelizes tentativas científicas de reaproximação do marxismo e da psicanálise nos anos 1970), o qual precisaria de um longo desenvolvimento sobre a inter (ou a pluri) disciplinaridade ${ }^{2}$ - o primeiro tipo permaneceu largamente invisível aos olhos dos pesquisadores. Dessa forma, as mudanças de escala - de análise dos grupos, dos movimentos, das estruturas ou das instituições, às quais os indivíduos singulares que, sempre ao mesmo tempo, "vivem em" e "são constitutivos de" esses macro-objetos - não foi tão brutal ao ponto de forçar a vista dos pesquisadores, de lhes provocar algumas dores de cabeça e, concomitantemente, de lhes fazer tomar consciência. 0 deslize foi insensível, imperceptível e tornou, desse modo, difícil o exercício da lucidez teórica. Sem mesmo se dar conta - e sem medir as conseqüências -, a sociologia se interessou tanto pelos indivíduos socializados como tais (nos estudos de caso ou nos trabalhos que apresentavam, entre outros tipos de "dados", os retratos individuais, sustentados metodologicamente pela prática das narrativas de vida ou de entrevistas aprofundadas), quanto pelos grupos, categorias, estruturas, instituições ou situações (quais sejam seus tamanhos e tipos). 0 movimento seria mais visível se os pesquisadores não tivessem o hábito de reivindicar a pertinência de suas propostas qual seja a escala de contextualização (do grupo social mais amplo ao indivíduo mais singular).

Entre o conjunto desses trabalhos desenvolvidos, uma corrente sociológica foi mais representativa que as demais - e caracterizou teoricamente essas "pequenas máquinas produtoras" de práticas (no sentido amplo do termo), essas "matrizes" que retêm no corpo de cada indivíduo o produto das experiências passadas. Quando, por exemplo, as noções (e as realidades às quais elas se remetem) de estruturas cognitivas, psíquicas ou mentais, de esquemas, disposições, habitus, incorporação e interiorização não estavam no âmago do estudo - servindo somente, nos relatórios das entrevistas, como conectores necessários para legitimar o motivo da adoção de práticas que evocam grosseiramente a socialização passada incorporada -, esses modelos teóricos poderiam parecer satisfatórios. Os termos emprestados da psicologia (principalmente piagetiana) permitiriam indicar um vazio ou uma ausência entre as estruturas objetivas do mundo social e as práticas dos indivíduos. 0 habitus, a mentalidade, a visão do mundo etc. poderiam então também ser tão grupais quanto individuais. Isso não coloca nenhum problema particular, pois não se presta uma atenção específica a essa questão e a teoria não se propõe verdadeiramente a estudar

2. LAHIRE, B. Certitudes et incertitudes des sociologues In: HARDY, M. (et al.) L'École et les changements sociaux, Montréal, Éd. Logiques, 1998. 
empiricamente essas referidas realidades. É razoavelmente suficiente ao ofício de sociólogo e, sem dúvida, o bastante também a uma grande parte dos pesquisadores contemporâneos. Dessa forma, vários sociólogos continuam a praticar a sociologia sem mesmo ter necessidade de dar um nome a essas matrizes corporais (cognitivas, sensitivas, valorativas, ideológicas, culturais, mentais, psíquicas etc.) dos comportamentos, das ações e reações. Alguns pensam mesmo que isso seja um problema típico das "caixas-pretas" (é assim com as noções de socialização e de habitus) das quais toda sociologia científica e explicativa deveria se afastar definitivamente ${ }^{3}$.

No entanto, não é possível falar de estruturas cognitivas, psíquicas ou mentais, de esquemas, disposições, habitus, incorporação ou de interiorização, sem ousar despertar a atenção e o questionamento crítico dos pesquisadores. Tudo que, até aqui, foi tomado como moeda corrente por uma certa tradição sociológica, e que avançava silenciosamente, pode então ser reconsiderado: Explicação disposicional? Esquema? Disposição? Sistema de disposições? Fórmula geradora ou princípio unificador de práticas? Habitus? Transposição ou transferência de esquemas? Herança cultural? Transmissão do capital cultural? Interiorização das estruturas objetivas? Incorporação das estruturas sociais? Universalizando as aquisições de um momento (não inteiramente acabado, evidentemente) da psicologia de seu tempo, uma parte da sociologia importou para seu seio, sob uma forma petrificada e praticamente inalterada há mais de trinta anos, conceitos psicológicos que não eram - como todo conceito científico - mais que espécies de abreviações dos trabalhos psicológicos mais avançados sobre a questão do desenvolvimento infantil daquele instante. Em vez de supor a existência de tais processos sociocognitivos, antecipando imprudentemente a longa e laboriosa série de atitudes de pesquisa que seria indispensável empreender, é necessário retornar aos caminhos da interrogação científica empiricamente fundada. Abre-se então o campo de uma sociologia psicológica cujas condições de emergência foram propiciadas, paulatinamente, por uma par- cela do mundo científico e cujo programa científico será aqui precisado ${ }^{4}$.

Estudar o social individualizado, isto é, o social refratado em um corpo individual - cuja peculiaridade é atravessar os diferentes grupos, instituições, campos de forças e de lutas e cenas -, é estudar a realidade social sob a forma incorporada, interiorizada. Como a realidade exterior, mais ou menos heterogênea, constitui corpos? Como as experiências socializadoras podem (co)habitar (dentro de) o mesmo corpo? Como algumas experiências se instalam mais ou menos duravelmente em cada corpo e como elas intervêm nos diferentes momentos da vida social ou da biografia de um indivíduo? Quando a sociologia se dedica a compreender os grupos de indivíduos a partir de uma prática ou de um domínio de práticas particulares (os assalariados de uma empresa, os conjuntos, os leitores, os usuários de determinada instituição cultural, os eleitores etc.), ela pode fazer a economia do estudo dessas lógicas sociais individualizadas. Todavia, desde que ela se interesse pelo indivíduo (não como átomo e base de toda análise sociológica, mas como produto complexo de múltiplos processos de socialização), não seria mais possivel se satisfazer com os modelos de ator, de ação e de cognição - implícitos ou explícitos - utilizados até o momento. Como pertinentemente sublinhou o historiador Giovanni Lévi: "nós não podemos [...] aplicar os mesmos procedimentos cognitivos com os grupos e com os indivíduos".

\section{O que é o social?}

É usual a tendência - tanto entre os não-sociólogos como entre grande parte dos sociólogos - de pensar que o social remete às diferenças entre grupos ou classes de indivíduos. A simples evocação, sem maior precisão, das

3. BOUDON, R. Social mechanisms without black boxes In: HEDSTRÖM, P. \& SWEDBERG, R. (orgs) Social mechanisms: na analytical approah to social theory, Cambridge, Cambridge University Press, 1996.

4. Cf. LAHIRE, B. L'homme pluriel: les ressorts de l'action, Paris, Nathan, 1998, p. 223-239.

5. LÉVI, G. Les usages de la biographie, ANNALES ESC, n. 6, novembredécembre, 1989, p. 1335. 
"diferenças sociais" significa tacitamente que se fala de diferenças entre classes sociais, categorias socioprofissionais ou socioculturais... Já se tem menos o reflexo de pensar nas diferenças, socialmente construídas, entre os sexos ou entre as gerações (entre matrizes de socialização). Entretanto, quase nunca surge espontaneamente a idéia de que a sociologia possa se interessar pelas diferenças mentais e/ou comportamentais entre dois indivíduos singulares, oriundos do mesmo meio social ou da mesma família. No entanto, tais diferenças interindividuais são o produto mesmo das relações sociais, das experiências sociais (socializadoras). Do mesmo modo, é muito raro entender o social por meio do estudo de casos estatisticamente atípicos, excepcionais ${ }^{6}$, ou do ponto de vista da variedade de diferentes situações sociais às quais um mesmo indivíduo está permanentemente vinculado ao longo do mais cotidiano de sua vida ${ }^{7}$.

É importante destacar, então, que o social não se reduz às relações sociais ou às diferenças sociais entre grupos ou categorias (quaisquer que sejam os critérios utilizados para caracterizálos), caso não se queira ensejar a visão de que diferenças mais sutis não seriam mais socialmente engendradas e que, por conseqüência, as estruturas cognitivas, emotivas, sensíveis, individuais... estariam fora da intelecção sociológica.

Os indivíduos são aquilo que suas múltiplas experiências sociais fazem deles. Assim, longe de ser a unidade mais elementar, o indivíduo é, sem sombra de dúvida, a realidade social mais complexa a ser apreendida. Compreende-se bem que a sociologia não poderia começar pela análise desses compostos complexos de experiências sociais heterogêneas, essas "misturas de estilos", segundo a bela expressão de Mikhaïl Bakhtine, que constituem os atores individuais. No fundo, contrariamente ao que as concepções elementaristas e atomistas possam nos fazer crer, é bem menos complexo estudar os universos sociais, os campos, os grupos sociais, as instituições ou as situações que os desdobramentos individuais do social. Cada indivíduo atravessou no passado - e o faz permanentemente - múltiplos contextos sociais (univer- sos, instituições, grupos, situações etc.); ele é o fruto (e o portador) de todas as experiências (nem sempre compatíveis, nem sempre acumulativas e, às vezes, altamente contraditórias) vividas nesses múltiplos contextos.

\section{A vida das disposiçōes}

0 desenvolvimento de uma sociologia psicológica implica que a própria noção de “disposição", central para se pensar o passado incorporado na escala individual, seja examinada. Ora, analisando minuciosamente a utilização desse conceito feita nos trabalhos sociológicos, dá-se conta rapidamente do fato de ele não ter recebido a devida importância (até o momento) como ferramenta de análise do mundo social $^{8}$. Assim, o sociólogo raramente aumenta o próprio conhecimento do mundo social nos usos rotineiros desse conceito. Por exemplo, quando Pierre Bourdieu explica que não existe práticas mais "classistas" que a freqüentação de um concerto ou a prática de um instrumento musical "nobre" pelo fato da "raridade das condições de aquisição das disposições correspondentes" ${ }^{\text {, }}$ ele tomou como verdadeiro algo sobre a função da distinção de certas práticas culturais, sobre sua raridade, mas não disse nada sobre o que seriam as tais "disposições correspondentes” a essas práticas. Da mesma forma, quando ele afirma que as obras literárias de Mallarmé ou de Zola carregam a marca das "disposições socialmente constituídas de seus autores" 10 , o leitor interessado se mostra inteiramente "disposto" a acreditar em sua interpretação, mas nenhuma análise das disposições desses autores, daquilo que se entende

6. LAHIRE, B. Tableaux de familles: heurs et malheurs scolaires em millieux populaires, Paris, Gallimard/Seuil, 1995.

7. GOFFMAN, E. Les cadres de l'experiénce, Paris, Minuit, 1991; BOLTANSKI, L. \& THÉVENOT, L. De la justification: les économies de la grandeur, Paris, Gallimard, 1991.

8. Por outro lado, quando dissociada a utilização das condições nas quais ela é iniciada-mobilizada, acaba-se por essencializá-la e reificá-la. Cf. LAHIRE, B. L'Homme pluriel, op. cit., p. 63-69.

9. BOURDIEU, P. La distinction: critique sociale du jugement, Paris, Minuit, 1979, p. 17.

10. Op. cit., n. 6, p. 19. 
precisamente por "disposições" e da maneira pela qual se poderia reconstruí-las, é proposta. As disposições sociais dos escritores, pertinentes para se compreender suas obras, são disposições sociais gerais adquiridas familiarmente, o produto específico da socialização literária (o que significaria que "tudo" da experiência socializadora dos autores não seria relevante reconstruir para apreender seus comportamentos literários)?

A revisão sistemática do conjunto dos contextos de uso da noção de disposição nas produções sociológicas leva a se colocar sempre tais questões. A utilização do termo pode ser específica, quando o autor emprega substantivos e adjetivos qualitativos (sem muita precisão, como ocorre em: "a disposição cultivada", "o conservadorismo pessimista") para caracterizar os tipos de disposições. A noção pode entrar, por outro lado, na economia geral da argumentação teórica ("a dialética que se estabelece completamente ao longo de uma existência entre as disposições e as posições"; "do ponto de vista de sua origem social e de todas as disposições correlativas").

No entanto, em todos esses casos, não há nenhum exemplo de construção social, de inculcação, de incorporação ou de "transmissão" dessas disposições. Não há nenhuma indicação sobre a maneira pela qual se pode reconstruí-las nem o modo pelo qual elas operam (isto é, como elas são ativadas ou colocadas em prontidão segundo os domínios de práticas ou contextos mais restritos da vida social). Elas são simplesmente deduzidas das práticas sociais (alimentares, esportivas, culturais etc.) mais freqüentemente observadas - estatisticamente - nas investigações.

A partir da constatação da inutilidade atual da noção, duas conclusões opostas podem ser tiradas: uma consiste em pensar o que se pode então fazer da sociologia sem esse tipo de conceito e que a economia (no duplo sentido do termo) conceitual dos modelos explicativos deva tender rumo à depuração e ao aperfeiçoamento do modelo (no qual as noções de disposição, de esquema ou de habitus seriam julgados supérfluos); a outra, aquela aqui formulada e que conduz ao programa de uma sociologia psicológica, leva a pensar que é necessário, de agora em diante, colocar à prova das pesquisas empíricas tal conceito retórico, a fim de fazê-lo passar ao estatuto de conceito cientificamente útil. Se a sociologia pretende permanecer uma sociologia disposicional, antes mesmo de se enfileirar ao lado das aproximações não-históricas e "dessocializantes" do mundo social (reduzido a uma gramática ou uma lógica da ação presente, aos sistemas de ação, à ordem presente de interação...), ela deve ir além da mera evocação ritual do passado incorporado, tomando por objeto a constituição social e o modo de vida desse passado.

Pergunta-se, então, por exemplo, como são formadas as disposições (ou os esquemas)? Essas disposições podem se extinguir progressivamente, chegando até mesmo a desaparecerem completamente por falta de atualização (Peirce dizia que as disposições podem "se cansar")? Poderiam elas, eventualmente, ser destruídas por um trabalho sistemático de contra-socialização (pensa-se em todas as intenções missionárias, sectárias, totalitárias ou escolares de destruição dos hábitos existentes, considerados como maus costumes a serem erradicados)? A possibilidade de avaliar os graus de constituição e de reforço das disposições segundo, principalmente, a freqüência e a intensidade da preparação contínua, distinguindo assim as disposições fracas (crenças passageiras e frágeis, hábitos efêmeros ou impróprios) e fortes, é desejável? Como as múltiplas disposições incorporadas, que não formam necessariamente um "sistema" coerente e harmonioso, se organizam ou se articulam?

Essa primeira série de questões mostra que não se abandonou verdadeiramente as questões mais clássicas da Sociologia da Educação, mesmo sendo elas aqui mais precisas e refinadas. Desse modo, é difícil compreender totalmente uma disposição sem reconstituir sua gênese (ou seja, as condições e modalidades de sua formação). Compreender as matrizes e os 
modos de socialização que formaram esse ou aquele tipo de disposição social deveria ser parte integrante de uma Sociologia da Educação concebida como uma sociologia dos modos de socialização (escolares e extra-escolares) e articulada a uma sociologia do conhecimento (no sentido mais amplo do termo "conhecimento"). Aliás, esse é um ponto da sociologia geral inscrito na reflexão weberiana:

Na medida em que a ação social é 'carregada' pelos homens ("por trás da 'ação' há o homem”), Weber sempre considerou que a análise social deveria integrar precisamente a questão 'do homem', aquilo que ele chama de 'ponto de vista antropocêntrico', ao se colocar a questão do 'tipo de homem' que as relações sociais são capazes de, em sua duração, moldar ${ }^{11}$.

\section{Formas de interiorização e de exteriorização}

0 programa científico de uma sociologia psicológica viria preencher o vazio deixado por todas as teorias da socialização ou da inculcação (como a teoria do habitus ou a teoria da "construção social da realidade", por exemplo) que se referem retoricamente à "interiorização da exterioridade" ou à "incorporação das estruturas objetivas" sem jamais verdadeiramente lhes "materializar" pela descrição etnográfica (ou historiográfica) e pela análise teórica. Por muito tempo, preocupados principalmente com a questão da reprodução social pela família, pela escola e as diferentes instituições culturais e sociais, os sociólogos se satisfaziam por constatar uma desigualdade face às instituições legítimas (escolas e outras instituições culturais) e/ou de uma herança cultural e social intergeracional (família). Em síntese, pode-se dizer que devido à reiterada insistência sobre o "isso se reproduziu", acabou-se por negligenciar o "o que se reproduziu" e o "como, segundo quais modalidades, isso se reproduziu". Resultado: uma teoria da reprodu- ção "plena", mas uma teoria do conhecimento e dos modos de socialização "vazia". 0 que é precisamente a escola? Quais são os vínculos de interdependência especificamente "escolares"? 0 que se "transmite" escolarmente? Como essa transmissão ${ }^{12}$ opera? As questões se colocam analogamente do lado da família e de toda instituição cultural ${ }^{13}$ ?

Uma parte das investigações da Sociologia da Educação e da cultura progressivamente induz ao estabelecimento de diferenças entre as modalidades da "interiorização do social" ou, mais exatamente, da interiorização ou incorporação dos hábitos, dos modos de fazer, de ver, de sentir. Percebe-se, então, principalmente pelas maneiras de falar de suas práticas culturais, que os entrevistados não incorporaram o conjunto de seus hábitos do mesmo modo. As pesquisas empíricas deveriam, por conseqüência, permitir precisar as diferentes maneiras pelas quais os hábitos incorporados e suas atualizações são vividas.

Dessa forma, nem tudo se explica sobre o modo da "necessidade feita virtude", isto é, pelo amor ao necessário, do prazer experimentado ao se praticar, consumir... aquilo do que não se pode escapar. Essa relação encantada com o mundo impede que se encare o fato de que as coisas poderiam se passar de outra forma, que uma outra escolha poderia ser feita. Uma vez que a coerção cultural inicial esteja fortemente interiorizada, a escolha se impõe por si mesma, aparecendo como natural e evidente. 0 modelo da "necessidade feita virtude" é aquele da coerção objetiva exterior transformada em motor interior, em gosto (ou em paixão) pessoal, em necessidade vital. Por exemplo, algumas crianças de meios populares parecem

11. GROSSEIN, J-P., Présentation In: WEBER, M. Sociologie des religions, Paris, Gallimard, 1996, p. 61.0 autor precisa que "o grau de unidade e de homogeneidade internas de uma conduta de vida não é pressuposta por Weber; só podendo ser estabelecido pela análise empírica".

12. A própria noção de "transmissão" deve ser revista, caso se queira progredir no sentido de uma sociologia psicológica dos fenômenos de conhecimento. Cf. LAHIRE, B. L'Homme Pluriel, op. cit., 1998, p. 206-210. 13. Para uma análise das modalidades da socialização escolar na escola primária, ver LAHIRE, B. Culture écrite et inégalités scolaires: sociologie de l'"échec scolaire" à l'école primaire, Lyon, PUL, 1993. 
ter precocemente interiorizado o "sucesso escolar" como uma necessidade interna, pesso$\mathrm{al}^{14}$. É necessária para isso uma configuração psíquica particular (ligada a uma economia socioafetiva singular que a análise sociológica das relações de interdependência permite reconstruir), que não consiste sem dúvida o caso mais freqüente. Desse ponto de vista, parece que quanto mais precoce - regular e intensa for a socialização (isto é, a instalação corporal dos hábitos), maior será a chance de ver aparecer essa lógica da "segunda natureza", do "é mais forte do que eu".

0 mesmo modelo supõe ainda que a disposição seja forte (e não fraca ou mediana) e proíba quase todo afastamento do papel. A adesão à prática é tal que toda dúvida é apagada. Não se resiste, não se é despertado por outros desejos, trabalhado por outras pulsões, cansado pelo investimento em outra prática... 0 modelo da "necessidade feita virtude" compõe de fato uma modalidade particular de existência do social incorporado e de sua atualização. Entretanto, a maneira encantada de viver seus hábitos não é a única, longe disso.

Assim, os indivíduos socializados podem ter interiorizado duravelmente um certo número de hábitos (culturais, intelectuais...) e não ter, entretanto, nenhum desejo particular de colocálos em uso. Ou ainda eles os coloquem em funcionamento por rotina, por automatismo, "por hábito", ou pior, por obrigação ("eu o faço, mas sou impelido a isso" ou "eu me forço"), sem paixão nem fascínio. Isso significa que é necessário distinguir claramente - com mais freqüência do que se costuma fazê-lo competências e apetências, "capacidades para fazer..." isso ou aquilo e gosto ou desejo de fazê-lo. Contrariamente à idéia comum em sociologia, que consiste em pensar que não se gosta muito daquilo que não se conhece bem e domina, as investigações sobre as práticas culturais permitem destacar duas dimensões bem distintas. Por exemplo, a descoberta de leitores contumazes ou de paixão pela leitura entre alunos que tenham competências fracas em francês e, inversamente, leitores fracos, pouco interessados pela cultura livresca, entre os alunos mais competentes, tanto nas escolas quanto nos liceus, permite dissociar competências e apetências. Se as competências culturais são geralmente uma condição favorável à aparição de uma prática assídua e apaixonada da leitura, elas não são suficientes para criar sistematicamente o leitor habitual ou o leitor entusiasmado ${ }^{15}$. Da mesma forma, em nível equivalente de competências, as mulheres são indiscutivelmente mais praticantes que os homens no domínio das práticas comuns da escrita. Elas desenvolvem suas competências mais pela posição (no universo familiar) que pela formação (escolar) ${ }^{16}$.

Por outro lado, certos hábitos podem ter sido duravelmente instalados no corpo de um indivíduo que, em um novo contexto de vida (por exemplo, todo acontecimento biográfico: casamento, nascença, divórcio, morte de um parente próximo, novo trabalho etc.), desejaria se livrar daquilo que ele considera doravante como "maus hábitos". Tudo se passa como se a nova situação o levasse a sentir uma parte de suas disposições ou hábitos como estranhas a si mesmo.

Os hábitos podem assim ser interiorizados e não serem atualizados senão pelo modo da coerção ou da obrigação; eles podem ser sobre o modo da paixão, do desejo ou da vontade ou, ainda, sobre o modo da rotina não consciente, sem verdadeira paixão nem sentimento de coerção particular. Tudo isso, por sua vez, dependerá da maneira pela qual foram

14. LAHIRE, B. Tableaux de familles, op. cit., p. 239-269.

15. De SINGLY, F. Les jeunes et la lecture, Les Dossier Éducation \& Formations, Paris, Ministère de l'Éducation nationale et de la Culture, DEP, n. 24, janvier 1993.

16. LAHIRE, B. Écritures domestiques: la domestication du domestique, Social Science Information / Information sur les sciences sociales, Londres, SAGE, vol. 34, n.4, 1995.

17. Algumas interiorizações apóiam-se nos mecanismos sociais-mentais tão potentes que a culpabilização pessoal (por exemplo, o caso das mães que interiorizaram algumas normas pediátricas para não se arriscar a sofrer acusações por serem "más mães") ou a chantagem mentalidentitária que repousa sobre as crenças mais fortes (como o conjunto dos suecos que sabiam ler em 1750 sob a pressão da Igreja luterana que impedia comunhão e casamento àqueles que não fossem capazes). 
adquiridas essas disposições ou esses hábitos ${ }^{17}$, do momento da biografia individual no qual eles foram adquiridos e, enfim, do "contexto" atual de sua (eventual) atualização. Assim, os hábitos que foram interiorizados precocemente, nas condições favoráveis a sua boa interiorização (sem fenômeno de injunção contraditória, sem ruído na "transmissão cultural" pelas dissonâncias culturais entre os pais ou entre aquilo que dizem os adultos e aquilo que fazem, entre o que dizem e a maneira como falam...) e que acham condições positivas (gratificantes socialmente) de pôr em prática, podem dar lugar àquilo que chamamos paixão, vontade ou desejo.

Poder-se-ia passar ao largo de certas nuances importantes do ponto de vista do grau de interiorização-instalação de hábitos, das condições nas quais eles o foram, das modalidades de sua aquisição e das condições nas quais são postos a "funcionar", considerando-se, da maneira mais rigidamente durkheimiana, que formulados na ilusória linguagem do amor, da rotina ou da coerção, os comportamentos individuais não são, em todos os casos, mais que a exteriorização do produto da interiorização das coerções sociais. Ao colocar, então, ao lado do senso comum e da ideologia, todo o discurso sobre a escolha, o desejo, a paixão, a espontaneidade, não se deu conta da negligência dos detalhes das condições, modalidades e efeitos da socialização.

Por que, salvo exceção, a interiorização de modelos de comportamentos sexuais é vivida de maneira diversa do modo de interiorização de uma obrigação, da coerção? No entanto, não há nada mais coercitivo e arbitrário (cultural, historicamente...) que os modelos sexuais, com o mundo social constituindo uma espécie de instituição total que socializa de maneira permanente os indivíduos a tais diferenças. 0 mundo social é continuamente supersaturado de diferenças sexuais. No entanto, é justamente porque essas diferenças são, às vezes, precoces e onipresentes que as coerções são raramente percebidas como tais ou, em todo caso, com bem menos força que outros tipos de coerções sociais. Se os hábitos e os modelos escolares de comportamentos e de pensamento são, por exemplo, mais vividos pelas crianças e pelos adolescentes sobre o modo da coerção, é porque a escola - qual seja seu grau de integração familiar - permanece sendo freqüentemente um universo relativamente "estrangeiro" e coercitivo, sobretudo quando exige um grau máximo de ascese, como nos períodos de preparação para provas e concursos. Se as crianças estavam submetidas ao duro regime da ascese escolar intensiva desde a escola primária, talvez a ascese do liceu, seguida de uma parte do Ensino Superior, seria vivida como normal, o que só é muito evidente em casos excepcionais.

\section{Transferência e estado de espera (stand by)}

Uma parte da sociologia toma também por moeda corrente, explícita ou implicitamente nos modos de interpretar os dados da investigação, a idéia de "transferabilidade" ou de "possibilidade de transposição" e do caráter "generalizável” dos esquemas ou das disposições socialmente constituídas. A noção de "transferabilidade", todavia, aumentou a imaginação sociológica ou, dito de outra forma, ela tornou possível investigações em ciências sociais que, sem ela, seriam impensáveis? Nada é menos certo. Para verificar que houve uma boa transferência, seria necessário estudar detalhadamente um modo de socialização e ver os efeitos precisos de sua difusão. Por exemplo, a socialização escolar produz efeitos de socialização julgados, geralmente - entre os sociólogos da Educação -, como duráveis e transferiveis. Entretanto, o que se transfere da situação escolar a outras situações extra-escolares? Um sentido da legitimidade dos produtos culturais (por exemplo, um sentido da "pequena" e da "grande" literatura)? Uma concepção geral do conhecimento, uma relação com o saber? Um número maior de gestos de estudo ou de hábitos intelectuais? Um sentimento pessoal da importância (da própria auto-estima) que essa instituição legítima pode conferir a todos aqueles que se conformarem a ela? Difícil dizer que tais processos de trans- 
ferência foram realmente colocados à prova em pesquisas empíricas.

Ao contrário, os sociólogos estão freqüentemente apoiados sobre tal noção, como sobre aquela de "generalizabilidade" das disposições e dos esquemas para reforçar uma certa preguiça empírica. Se cada investigação, sobre essa ou aquela prática, permitisse verdadeiramente compreender as disposições gerais, que se pressupõe transferiveis a outras situações, evitar-se-ia então, dessa forma, um longo e cansativo percurso de pesquisa ${ }^{18}$ : aquilo mesmo que uma sociologia psicológica se propõe - como contribuição - a executar.

Emprestada da psicologia piagetiana, a noção de "transferabilidade" suscita hoje em dia a crescente desconfiança de uma parte dos psicólogos contemporâneos ${ }^{19}$. No entanto, é sobretudo o processo de generalização abusiva ou prematura que constitui o problema essencial que se origina pelo uso de tal noção. É, dessa forma, a idéia, segundo a qual os esquemas ou as disposições seriam todas e em todas as ocasiões transferíveis e generalizáveis, que traz problemas ${ }^{20}$. 0 pesquisador "curto-circuita"\# a marcha normal da investigação e evita a difícil comparação das práticas de um domínio de práticas com outro ou mesmo de uma situação com outra no interior de uma mesma esfera de atividade, que só permitiria dizer: 1) se a transferência foi bem sucedida; e 2) qual é sua natureza. Deduzir precipitadamente da análise das práticas de um indivíduo ou de um grupo social em um contexto determinado (qual seja a escala do contexto) os esquemas ou as disposições gerais, os habitus que funcionariam paralelamente em todos lugares, em outros locais e em outras circunstâncias, constituiria então um erro de interpretação.

As diferenças de comportamento observáveis de um contexto a outro não seriam apenas o produto da refração de um mesmo habitus (de um mesmo sistema de disposições) dentro de contextos diferentes? De fato, o regime, não discutido e empiricamente pouco submetido à prova de transferência generalizada, impede conceber (e, logo, de observar) a existência de esquemas ou de disposições de aplicação fortemente locais (próprias das situações sociais ou dos domínios de práticas particulares), de modos de categorização de percepção, de apreciação ou de ação sensório-motora parciais vinculadas a objetos ou a domínios específicos. Reduz-se um complexo processo de "exteriorização da interioridade" a um funcionamento único e simples, a saber aquele da assimilação/acomodação: assimilação das situações aos esquemas incorporados e acomodação (correção) dos esquemas anteriormente adquiridos às variações e trocas de situações.

E se, em vez de se generalizar, as disposições fossem às vezes total e simplesmente inibidas ou desativadas para dar lugar à formação ou à ativação de outras disposições? E se elas pudessem se limitar a não serem mais que disposições sociais específicas, no domínio de pertinência bem circunscrito, o mesmo indivíduo aprendendo a desenvolver disposições diferentes em contextos sociais diferentes? E se, no lugar do simples mecanismo de transferência de um sistema de disposições, tenha-se relação com um mecanismo mais complexo de deixar em estado de espera/colocar em ação ou de inibição/ativação de disposições que supõem, evidentemente, que cada indivíduo singular seja portador de uma pluralidade de disposições e atravesse uma pluralidade de contextos sociais?

Os esquemas interpretativos dos comportamentos humanos que Jon Elster formula a partir

18. Quando, desejando separar disposição e regularidade de aparição de uma prática, Emmanuel Bourdieu escreve que somente uma única ocorrência de um comportamento "é um critério necessário e suficiente" do fato que o indivíduo "possui uma disposição a ter esse comportamento" (Savoir faire: contribuition à une théorie dispositionelle de l'action, Paris, Seuil, 1998, p. 45), ele não se dá conta, de uma parte da necessidade, para o trabalho interpretativo em ciências sociais, de se apoiar em uma série de dados e não sobre observações isoladas, e, por outro lado, da fantástica preguiça empírica que encorajaria a adoção de tal disposição.

19. LOARER, E. et al., Peut-on éduquer l'intelligence? L'évaluation d'une méthode d'éducation cognitive, Berne, Peter Lang, 1995.

20. Utilizador do conceito de habitus, Max Weber não o concebe fortemente como um sistema de disposições gerais. Ele poderia escrever assim: "Esse estado poderia corrensponder a um habitus extracotidiano de caráter apenas passageiro" (Sociologie des religions, op. cit., p. 347).

\# N. T.: Flexão do verbo "cuto-circuitar", o qual, além de indicar a ação de colocar em curto-circuito (algo mais próximo ao nosso entendimento), denota a ação de saltar um intermediário, passando por uma via mais curta que a normal. 
de sua leitura do texto de Alex de Tocqueville, A democracia na América, nos parecem característicos de uma interpretação do mundo social que, sem o saber, desafia o problema da pluralidade de esferas de atividade atravessadas por cada indivíduo, ele mesmo portador de uma pluralidade de disposições. Elster escreveu: "Os hábitos e os desejos podem se reforçar, se compensar e se limitar uns aos outros, por três mecanismos que chamarei o efeito de transbordamento, o efeito de compensação e o efeito de soma zero" ${ }^{21}$. 0 efeito de transbordamento é um efeito de transferência: "Os hábitos adquiridos em uma esfera são transferidos para outra”. O efeito de compensação supõe da parte do indivíduo que "aquilo que ele não acha em uma esfera, ele procura em alguma outra". Enfim, o efeito de soma zero está ligado à impossibilidade de se ter uma infinidade de investimentos sociais, o investimento em uma esfera de atividade que explique a ausência ou a diminuição na mesma medida que os outros.

Poder-se-ia julgar tão duramente essa aparente obsolescência teórica que pode identicamente "fazer referência à presença do fenômeno mental $A$ na esfera $X$ para explicar porque $A$ está também presente na esfera $Y$ : é o efeito de transbordamento", quanto "fazer menção à ausência de $A$ em X para explicar sua presença em Y: é o efeito de compensação" ou, ainda, "fazer referência a sua presença em $X$ para explicar porque está ausente em Y: é o efeito de soma zero" ${ }^{22}$. Entretanto, então se passaria ao largo de certas características do funcionamento do mundo social em uma sociedade diferenciada. Dessa forma, o efeito de transferências se explica pela analogia das situações passadas com as presentes: quando construíram uma parte de suas disposições em algumas situações, os indivíduos as colocaram em funcionamento em situações análogas. 0 efeito de compensação não pode ser compreendido a não ser admitindo-se que o indivíduo é portador de disposições heterogêneas (e mesmo contraditórias): forçado a colocar em stand by, a inibir uma parte de suas disposições sociais em uma esfera de atividade (a vida pú- blica, por exemplo), ele os deixa se exprimir em uma outra esfera (como a vida privada). Enfim, o efeito de soma zero não pode ser compreendido sobre o mesmo registro. Ele se ancora, sobretudo, na constatação antropológica que o volume de tempo do qual nós dispomos é uma quantidade finita. 0 tempo dispensado em um domínio é um tempo que não será investido em outros: assim, se nossas disposições sociais nos induzem a investir com ardor no universo profissional; no universo doméstico, seremos mais relaxados. A pluralidade dos mundos ou dos âmbitos sociais é assim também um problema para cada indivíduo que deve dividir seu tempo entre esses diferentes universos.

Como o indivíduo vive a pluralidade do mundo social assim como sua própria pluralidade interna? 0 que produz essa pluralidade (externa e interna) sobre a economia psíquica e mental dos indivíduos que a vivem? Em quais disposições o indivíduo investiu nos diferentes universos (no sentido mais comum do termo) que foi levado a atravessar? Como distribui sua energia e seu tempo entre os mesmos universos? Eis aqui uma série de questões que uma sociologia psicológica, em escala do indivíduo, necessariamente se coloca.

\section{O singular plural}

Por um simples efeito de escala, a compreensão do singular enquanto tal, ou seja, do indivíduo como produto complexo de diversos processos de socialização, força a ver a pluralidade interna do indivíduo: o singular é necessariamente plural. A coerência e homogeneidade das disposições individuais pensadas pelas sociologias em escala de grupos ou das instituições é substituída por uma visão mais complexa do indivíduo

21. ELSTER, J. Psychologie politique, Paris, Minuit, 1990, p. 181.

22. 0p. cit., p. 185.

23. 0 estudo de caso de "trânsfugas de classe" é essencial afim: 1) de compreender como um indivíduo pode incorporar disposições contraditórias, como ele vive com essa contradição (sufocando ou deixando em espera suas antigas disposições?, cindindo-separando muito sensivelmente os universos nos quais ele colocará em funcionamento essas ou aquelas disposições?, sofrendo a cada instante da contradição entravante das disposições?); e 2) de avaliar em que medida a pluralidade relativa das disposições portadas pelos indivíduos redunda ou não em conflitos psíquicos ou em cãibras identitárias. 
menos unificado e portador de hábitos (de esquemas ou de disposições) heterogêneos e, em alguns casos, opostos, contraditórios ${ }^{23}$.

As Ciências Sociais (principalmente a Sociologia, a História e a Antropologia) viveram durante longo tempo sobre uma visão homogeneizadora do indivíduo em sociedade. Pesquisar sua visão do mundo, sua relação com o mundo ou "a fórmula geradora de suas práticas" (o habitus) foi considerado - e ainda permanece acentuadamente até hoje - como uma marcha rumo a si. Retorcendo o argumento em outro sentido, algumas sociologias pós-modernas parecem, no entanto, ao contrário, se deliciar com a idéia de dispersão, explosão, fragmentação ou disseminação infinita do ator.

Logo, não é questão de se decidir de uma vez por todas, a priori, a questão (do grau) da unidade ou pluralidade do ator individual, mas de se questionar quais são as condições sociohistóricas que tornam possível a produção de um ator plural ou de um ator caracterizado por uma profunda unidade. A escolha da unidade ou da fragmentação constitui, na maior parte do tempo, um postulado não discutido e se funda, em alguns casos, mais sobre pressupostos éticos do que sobre constatações empíricas. De fato, a coerência (relativa) dos hábitos (de esquemas ou de disposições) que podem ter sido interiorizados por cada indivíduo dependerá da coerência dos princípios de socialização aos quais ele foi submetido. Quanto mais um indivíduo foi colocado, simultânea e sucessivamente, no seio de uma pluralidade de contextos sociais não homogêneos e, às vezes, até mesmo contraditórios, mais essa experiência foi vivida de maneira precoce e mais diz respeito a um indivíduo possuidor de disposições, hábitos ou capacidades não homogêneas, não unificadas, que variam de acordo com o contexto social no qual ele será levado a evoluir.

\section{As múltiplas inscrições contextuais}

Com exceção de uma parte das pesquisas de natureza sociolingüística particularmente sensíveis às variações contextuais (David Efron, William Labov, John Gumperz...), raros são os trabalhos sociológicos que se atribuem o objetivo de comparar as práticas de um mesmo indivíduo (e não globalmente de um grupo de indivíduos) em esferas diferentes de atividade, em universos sociais diferentes, em tipos de interação diferentes. Ao estudar indivíduos sobre cenas particulares, no âmbito de um só domínio de práticas (seguido de um recorte subdisciplinar particularmente contestável cientificamente: sociologia da família, da educação, da cultura, da arte, do trabalho, da saúde, da juventude, sociologia religiosa, política, jurídica...), esforça-se bastante, equivocadamente, em deduzir da análise dos comportamentos observados sobre essas cenas de disposições gerais, os habitus, as visões de mundo ou as relações gerais com o mundo.

Uma parte do programa sociológico aqui proposto implica exigências metodológicas novas. Para apreender a pluralidade interna dos indivíduos e a maneira pela qual ela age e se "distribui" de acordo com os contextos sociais, é necessária a adoção de dispositivos metodológicos que permitam observar diretamente - ou reconstruir indiretamente, por diversos recursos - a variação "contextual" (no sentido amplo do termo) dos comportamentos individuais. Apenas tais dispositivos metodológicos permitiriam julgar em qual medida algumas disposições são transferiveis de uma situação a outra - enquanto outras não de ver como opera o mecanismo de inibiçãoestado de espera/ativação-colocação em funcionamento das disposições e de avaliar o grau de heterogeneidade ou de homogeneidade da posse de hábitos incorporados pelos indivíduos no percurso de suas socializações anteriores. Se a observação direta dos comportamentos permanece sendo o método mais pertinente, ela é raramente possível na medida em que "acompanhar" um indivíduo nas diferentes situações de sua vida é uma tarefa ao mesmo tempo difícil e deontologicamente problemática. No entanto, mesmo a entrevista e o trabalho sobre arquivos podem ser reveladores - quando se está mais sensível às 
diferenças que às permanências - de múltiplas pequenas contradições, de heterogeneidades comportamentais não percebidas pelas investigações que geralmente tentam, pelo contrário, manter a ilusão da coerência e da unidade do "próprio eu".

É preciso não somente comparar as práticas dos mesmos indivíduos em universos sociais (mundos sociais que podem, em certos casos, mas não sistematicamente, se organizar sob a forma de campos de lutas), tais como o mundo do trabalho, a família, a escola, a vizinhança, a igreja, o partido político, o mundo do lazer, as instituições culturais etc., mas também diferenciar as situações no interior desses diferentes grandes domínios - nem sempre também perceptivelmente separados na realidade social -, considerando as diferenças intra... (familiares, profissionais...).

\section{A produção do indivíduo}

Um programa que se interesse pelo mundo social na escala do indivíduo, pelo social individualizado, não pode fazer a economia do estudo das condições sociais (e discursivas) da produção do indivíduo moral e ideológico como um ser isolado, coerente, autônomo, singular, fundamentalmente fechado sobre si mesmo antes de todo contato com outros, que disponha de uma interioridade ou de um "eu autêntico". Se a sociologia psicológica se interessa pelo sujeito empírico (no sentido de Louis Dumont) e pelas lógicas sociais apreendidas na escala desse sujeito empírico (que não tem nenhuma espécie de semelhança com o indivíduo dessocializado do individualismo metodológico), ela não pode deixar de se interessar pela produção da imagem (moral, ideológica...) do eu individual.

Essa produção do indivíduo como indivíduo singular, autônomo, é freqüentemente entendida pelo conteúdo dos discursos (ideológicos, filosóficos...) $)^{24}$, mas não se pode negligenciar o estudo das instituições, dos dispositivos sociais ou das configurações de relações de interdependência que contribuem na produção desse sentimento de singularidade, de autonomia, de interioridade, de identidade de si a $\mathrm{si}^{25}$.

Um canteiro de pesquisa poderia ser também utilmente constituído no sentido de uma história e/ou de uma sociologia das formas de unificação discursiva (principalmente narrativa) do "eu". A ilusão de um eu unificado, homogêneo, coerente, não carece de fundamento social. Poder-se-ia mesmo dizer que a celebração da unidade de si é uma empresa permanente em nossas sociedades. A começar pelo "nome próprio" associado ao "prenome", simbolizado na assinatura manuscrita, que consagram a inteira singularidade da "pessoa" e que nos acompanham durante toda nossa vida, e terminando por todas as formas discursivas de apresentação de si, de sua história, de sua vida (curriculum vitae, elogios fúnebres, notícias necrológicas, apologias, biografias e autobiografias, narrativas de vida, bildungsroman, reconstituição da vida do acusado perante um tribunal...). Em numerosos desses gêneros discursivos, o postulado da unidade do sujeito é forte. 0 "eu" que se exprime ou o "ele" que é narrado garantem uma série de perenidades e de permanências de uma unidade pessoal coerente e uniforme.

Enfim, um diálogo renovado é assim possível com a história a propósito da prática da biografia histórica ${ }^{26}$. Como modificar o gênero biográfico que privilegia, tanto quanto o gênero discursivo, a coerência de uma trajetória, de uma vida, de uma caminhada..., à custa de todas as incertezas, as incoerências, ou mesmo as contradições pelas quais são molda-

24. Cf. DUMONT, L. Essais sur l'individualisme: une perspective anthropologique sur l'idéologie moderne, Paris, Seuil, 1983 ou TAYLOR, C. Les sources du moi: la formation de l'identitémoderne, Pari, Seuil, 1998. 25. Cf. ELIAS, N. La societé des individus, Paris, Fayard, 1991, p. 6467. Nós trabalhamos, por nosso turno, a maneira pela qual a escola elementar contribui para formar o aluno autônomo, entendendo a autonomia como uma forma de dependência histórica específica e a escola como 0 lugar onde se opera a aprendizagem progressiva dessa nova relação com o poder e com o saber.

26. Retoma-se assim a vontade exprimida por Giovanni Lévi quando instou a reconsiderar-se a "tradição biográfica estabelecida", assim como a "própria retórica" da história, que repousa sobre "modelos que associam uma cronologia ordenada, uma personalidade coerente e estável, ações sem inércia e decisões sem dúvidas" (Les usages de la biographie, op. cit., p. 1326). 
das as personagens históricas reais. É preciso não ceder, de forma alguma, à ilusão positivista de poder compreender a totalidade de uma "personalidade", em todas as facetas de sua existência ou, como às vezes ainda se diz, "em toda sua complexidade". No entanto, evitar o apagamento ou a eliminação sistemática dos dados heterogêneos e contraditórios, pelo cruzamento dos dados de arquivos sobre o mesmo indivíduo, pela compreensão de aspectos muito diferentes de sua atividade social em vez de simplesmente construir o retrato coerente dele como artista, escritor, rei, guerreiro, homem de Estado ou da lgreja sob pretexto que a ciência é forçosamente simplificadora e que a reconstrução científica é inevitavelmente mais coerente que a realidade ou que a ciência coloca necessariamente em ordem a desordem relativa do mundo empírico -, é uma maneira de renovar o gênero biográfico, transformando-o em história, fazendo-o um lugar experimental (no sentido de lugar de experiências, de ensaios) de importante reflexão metodológica.

\section{A generalidade do singular}

Contrariamente àquilo que se poderia crer no primeiro momento, a sociologia psicológica não se opõe de nenhum modo às aproximações estatísticas. Não somente ela se nutre das constatações e das análises da sociologia estatisticamente fundada como as boas investigações estatísticas permitem sempre pesquisar as variáveis mais reveladoras das diferenças em função do domínio de práticas estudado e, logo, possibilitam identificar as disposições sociais que são mais particularmente mobilizadas nesse ou naquele contexto específico pelas categorias dos indivíduos. A sociologia psicológica não tem então por especialidade se ocupar de casos teatrológicos, excepcionais, estatisticamente atípicos e improváveis..., ainda que tais casos, às vezes, lhe sejam úteis para fazer aparecer alguns dos problemas que ela pretende tratar especificamente (por exemplo, o caso dos "trânsfugas").

Como mostra o estudo histórico de um caso atípico de Carlos Ginzburg, a saber, aque- le de um moleiro chamado Menocchio ${ }^{27}$, o entendimento do singular passa necessariamente pela compreensão do geral - e pode-se dizer que não há nada mais geral que o singular. Pouco a pouco, chega-se a compreender como - segundo quais desdobramentos, de acordo com quais fissuras específicas de propriedades gerais, de experiências nas formas de vida sociais - Menocchio tornou-se aquilo que é. Para compreender o social no estado desdobrado, individualizado, é necessário ter um conhecimento do social ao estado desdobrado; ou, dito de outra forma, para atribuir razão à singularidade de um caso, é preciso compreender os processos gerais dos quais esse caso não é mais que o produto complexo.

Uma vez que o próprio Ginzburg se refere a Conan Doyle e a seu herói, Sherlock Holmes, para explicitar o "paradigma indicativo" no qual se inscrevem seus trabalhos, poder-se-ia aqui se basear no trabalho de investigação desse último para mostrar que chegar a converter detalhes insignificantes em detalhes reveladores, isto é, em índices dessa ou daquela propriedade, prática, disposição ou traço de caráter, supõe um conhecimento geral (histórico, geográfico, antropológico, econômico...) do mundo social e de suas tendências históricas, pelas quais eles foram estatisticamente estabelecidos ou reconstruídos sobre bases documentárias, observações diretas ou testemunhos... Assim, Sherlock Holmes não chegou a operar suas deduções a não ser sobre a base de um incrivel conhecimento erudito: ele apóia sua argumentação sobre o conhecimento que tinha de alguns hábitos profissionais, culturais, nacionais... Longe de repousar sobre conhecimentos singulares, elas supunham a efetivação de conhecimentos gerais mobilizados em vista de uma compreensão de um caso singular.

A idéia, que vem espontaneamente ao espírito em face de tudo aquilo que pode parecer estudo de caso, é aquela da fraca representatividade estatística dos casos estudados. Ao estudo do caso

27. GINZBURG, C. Le fromage et les vers: I'univers d'um meunier du XVle siècle, Paris, Flammarion, 1980. 
singular, costuma-se opor o conhecimento das tendências gerais, das recorrências do mundo social estatisticamente apreendidas. Entretanto, "singular" não significa "não sujeito à repetição" ou "único". Ao constituir o singular como o inverso do geral, atualiza-se uma velha oposição entre ciências nomotéticas e ciências idiográficas, método generalizante e método individualizante ${ }^{28}$ que não recuperou a pertinência.

Paradoxalmente, o estudo de caso, em sua singularidade - e não a título de caso ilustrativo por relação às figuras idealtípicas ou às tendências ou propriedades gerais estatisticamente associadas mais freqüentemente a um grupo -, pode restituir às situações estatisticamente mais freqüentes muito mais do que se acredita. Desse modo, os pesquisadores em Ciências Sociais trabalham quase sempre utilizando dicotomias que lhes permitem ver como se distribuem os diferentes grupos ou categorias de indivíduos entre os dois pólos opostos. Por exemplo, a Sociologia da Educação pode opor os estudantes conforme suas tendências ascéticas ou hedonistas. Poder-se-á, assim, obter duas figuras idealtípicas do espírito dos estudantes, a saber: de um lado, o estudante asceta, inteiramente voltado ao trabalho escolar, que sacrifica tudo (sociabilidade amical, sentimental e familiar, lazer e viagens...) para se dedicar aos estudos e, de outro, o estudante boêmio, amante de festas, de lazeres, de amizades, de amores e que trabalha de maneira forçosamente descontínua, ocasional $^{29}$. No entanto, ao se procurar na realidade os estudantes que correspondem melhor a esses dois pólos, arrisca-se a não se ter - estatisticamente - mais que um punhado de candidatos. A grande maioria deles estaria entre os dois, em situações "medianas" que são, de fato, as situações mistas, ambivalentes: eles não são nem máquinas de trabalho nem arroz-de-festa, mas alternam, de acordo com os contextos e, sobretudo, seus entornos (e suas pressões) no momento, épocas de dedicação ao trabalho e momentos de relaxamento, sofrendo alternativamente da dor de sua adoção do ascetismo e da dor-de-consciência do estudante hedonista ${ }^{30}$. Portadores de disposi- ções (mais ou menos fortemente constituídas) relativamente contraditórias, eles são mais numerosos estatisticamente que seus companheiros "exemplares" (do ponto de vista da referida oposição teórica). E mesmo os estudantes mais típicos dos pólos opostos poderiam ser trabalhados pelos desejos contraditórios, ao menos simbolicamente.

Da mesma forma, quando o sociólogo da Educação tenta compreender os processos de "fracasso" e de "sucesso" escolares a partir da oposição conceitual entre dois tipos de códigos sociolingüísticos (restrito e elaborado) ${ }^{31}$, duas arbitrariedades culturais (o arbitrário cultural dominante e o dominado) ${ }^{32}$, dois tipos de relações com a linguagem (relação escrita-escolar com a linguagem e relação oralprática com a linguagem) ${ }^{33}$, ele geralmente concentra sua análise sobre os pólos de oposição, esquecendo-se das situações mistas e ambivalentes dos alunos "medianos" cujas disposições escolares não são inexistentes, mas fracas ou, em todo caso, não fortes o suficiente para se impor sistematicamente face às disposições não escolares. Não é um mero acaso epistemológico o fato de os sociólogos da Educação estarem essencialmente voltados a dar explicações aos casos de "sucessos" e aos casos de "fracassos" escolares, negligenciando totalmente o caso desses alunos "medianos". No entanto, mesmo no caso das crianças com grande dificuldade escolar, elas não saem jamais intactas da escola e desenvolvem também comportamentos escolares ambivalentes ${ }^{34}$.

Não se pode então criticar o programa da sociologia psicológica por se limitar ao estudo interessante, mas secundário e mesmo marginal das exceções estatísticas, muito pelo contrário. Paradoxalmente, vários pesquisadores, ao comen-

28. FREUND, J. Sociologie de Max Weber, Paris, PUF, 1983, p. 32-36. 29. Cf BOURDIEU, P. \& PASSERON, J-C. Les héritiers, les étudiants et la culture, Paris, Minuit, 1964 et LAHIRE, B. Les manières d'étudier, Paris, La Documentation française, 1997.

30. LAHIRE, B. L'homme pluriel, op. cit., 1998, p. 76-79.

31. BERNSTEIN, B. Langage et classes sociales, Paris, Minuit, 1975.

32. BOURDIEU, P. \& PASSERON, J-C. LA reproduction: éléments pour une théorie du système d'enseignement, Paris, Minuit, 1970.

33. LAHIRE, B. Culture écrite et inégalités scolaires, op. cit.

34. Op. cit. 
tarem seus quadros estatísticos, interpretaram seus dados a partir da lógica das aproximações relativas das categorias ou grupos de indivíduos com os referidos pólos de oposição pretendidos, deixando de lado, ao mesmo tempo, a compreensão dos casos intermediários - geralmente os mais numerosos, os mais comuns. 0 exemplo (mais) “perfeito", que às vezes condensa ou acumula o conjunto das propriedades estatisticamente mais ligadas a um grupo ou a uma categoria, é sem dúvida necessário quando se quer ilustrar uma análise baseada em dados estatísticos. Ele é freqüentemente utilizado para compor o retrato de uma época, de um grupo, de uma classe ou de uma categoria. Todavia, esse exemplo pode se tornar enganoso e caricatural a partir do momento em que não lhe é conferido - explicitamente - o estatuto de ilustração (representante de uma instituição, de uma época, de um grupo...), mas tomado como um caso particular do real, ou seja, como o produto complexo e singular de múltiplas experiências socializadoras. Pois a realidade social encarnada em cada indivíduo singular é sempre menos clara, menos simples que essa. Aliás, as escolhas efetuadas pelas grandes pesquisas indicam as propriedades (recursos, atitudes, práticas...), estatisticamente mais vinculadas a tal grupo ou tal categoria; é impossível deduzir daí que cada indivíduo componente do grupo ou da categoria (nem mesmo da maioria deles) reúna a totalidade (nem mesmo a maioria) dessas propriedades.

Do mesmo modo, por tentar compreender as combinações relativamente singulares das propriedades gerais, a sociologia psicológica encontra algumas dificuldades com um certo uso do método idealtípico. Se o sociólogo se contenta em produzir quadros coerentes sem fornecer para exame casos menos homogêneos, menos claros, mais ambivalentes, então, ele apresenta um social (e principalmente casos individuais) estranhamente coerente e quase inexistente. 0 método idealtípico aponta, então, claramente para o sentido de uma compreensão do social "desdobrado" e "des-heterogeneizado". A dificuldade vem menos de Weber, consciente do fato que os "elementos heterogêneos por si mesmos são compativeis" ${ }^{35}$, e que os homens não foram jamais "livros pormenorizados em todos os detalhes", ainda mais que eles não foram "construções lógicas ou isentos de contradições psicológicas”36, mas vêm de seus intérpretes, que confundem, como disse Marx, a lógica das coisas com as coisas da lógica.

\section{As razões da sociologia psicológica}

Ao voltar a atenção à análise das marcas mais singulares do social, a sociologia em escala do indivíduo, ou sociologia psicológica, se inscreve na longa tradição sociológica que, de Émile Durkheim a Norbert Elias (passando por Maurice Halbwachs), visa ligar cada vez mais finamente a economia psíquica aos moldes da vida social. Tal estudo supõe a adoção de ferramentas conceituais e metodológicas adequadas.

No entanto, pode-se logicamente se perguntar qual(ais) razão(ões) possue(m) o sociólogo para estudar o social em escala individual. Escolhendo um tal ponto de vista do conhecimento da realidade, não se está em vias de comungar e de acompanhar ativamente o movimento de individualização que conhecem nossas formações sociais? Fora da dinâmica própria do campo sociológico, que explica, como aqui indicamos introdutoriamente, que tal interesse aponta no sentido de um progresso da autonomia científica da disciplina, é evidente que essa sociologia responde a uma necessidade histórica de pensar o social em uma sociedade fortemente individualizante. No momento em que o homem pode ser cada vez mais concebido como um ser isolado, autônomo, dotado de razão, "sem amarras nem raízes", oposto à "sociedade", contra a qual ele defenderia sua "autenticidade" radical, a sociologia tem o dever (e o desafio) de atualizar a produção social do indivíduo (e a concepção que se tem deste) e de mostrar que o social não se reduz

35. WEBER, M. Sociologie des religions, op. cit., p. 206.

36. 0 p. cit., p. 364. 
ao coletivo ou ao geral, mas que avança nas marcas mais singulares de cada indivíduo.

Desse ponto de vista, a sociologia deveria se focar em produzir uma visão do homem em sociedade de modo mais científico que as (necessárias) caricaturas feitas quando se imagina o indivíduo a partir de figuras idealtípicas retiradas dos trabalhos sobre grupos sociais, épocas históricas ou instituições. Ela deveria, sobretudo, ser capaz de responder às questões comuns, profanas mais essenciais, quanto à vida dos indivíduos em sociedade. Por exemplo, como compreender que um indivíduo possa surpreender seu entorno próximo (onde há, portanto, pessoas que chegam ao ponto de elaborar um conhecimento intuitivo-prático desse indivíduo) e mesmo surpreender-se a si mesmo pelo fato de ter sido capaz de fazer isso ou aquilo, em tal circunstância ou em tal momento de sua biografia? Qual concepção do determinismo social deve-se ter para descobrir a razão dessa indeterminação relativa do comportamento individual que faz o charme da vida social?

É, dessa forma, impossível prever a aparição de um comportamento social como se prediz a queda dos corpos a partir da lei universal da gravidade. Essa situação é o produto da combinação de dois elementos: de um lado, a impossibilidade de reduzir um contexto social a uma série limitada de parâmetros pertinentes como no caso das experiências físicas ou químicas e, por outro lado, a pluralidade interna dos indivíduos cujo patrimônio de hábitos (de esquemas ou de disposições) é mais ou menos heterogênea, composto de elementos mais ou menos contraditórios. Dificilmente se conseguiria predizer com certeza o que, em um contexto específico, vai "jogar" ("pesar") sobre cada indivíduo e o que, dos múltiplos hábitos incorporados por ele, será deslanchado em/por tal contexto. A constatação sociológica que somos obrigados a tirar de nosso conhecimento atual do mundo social é que o indivíduo é tão multissocializado e tão multideterminado que se torna difícil crer que possa ter consciência de seus determinismos. É desse ponto de vista (sócio)lógico que se vê os indivíduos resistirem fortemente à idéia de um determinismo social. É por ter grandes chances de ser plural e por se exercerem, sobre ele, "forças" diferentes conforme as situações sociais nas quais ele se encontra que o indivíduo pode ter o sentimento de uma liberdade de comportamento.

Essa idéia complexa e sutil do determinismo social sobre os comportamentos individuais foi, de uma certa maneira, já apropriada por parte da literatura, principalmente por Marcel Proust. Já quase-teoricizando sobre a pluralidade do "eu" em cada indivíduo ${ }^{37}$, em seu Contre Sainte-Beuve, o romancista desenvolveu uma escrita literária que não somente colocou em cena essa pluralidade de heranças e de identidades individuais, mas deu um exemplo de uma "sociologia individual" sutilmente determinista ${ }^{38}$.

Enfim, é 1) porque cada um de nós pode ser portador de uma multiplicidade de disposições que não se acham sempre os contextos de sua atualização; 2) porque nós podemos ser desprovidos de boas disposições que permitam fazer face a algumas situações mais ou menos inevitáveis em nosso mundo social multidiferenciado; e 3) porque a multiplicidade dos investimentos sociais (familiares, profissionais, amicais...) objetivamente possíveis podem se tornar, no final das contas, incompatíveis, que nós podemos viver inquietos, em crises ou em conflitos pessoais com o mundo social. Primeiramente, sentimentos de solidão, incompreensão, frustração, mal-estar podem ser frutos dessa (inevitável) distância entre o que o mundo social nos permite "exprimir" objetivamente em um determinado momento do tempo e o que foi posto em nós ao longo de nossa socialização passada. Porque somos portadores de disposições, capacidades, saberes e habilidades que talvez vivam em permanente estado de espera por razões sociais objetivas, nós podemos então sentir um mal-estar que se traduz geralmente por ilusão de que nosso "eu autêntico"

37. LAHIRE, B. L'homme pluriel, op. cit., p. 43-46.

38. DUBOIS, J. Pour Albertine: Proust et le sens du social, Paris, Seuil, 1997, p. 130. 
("pessoal” e, logo, pensado como associal) não encontraria seu lugar nos moldes limitados da sociedade (assimilada a um conjunto de normas sociais estranhas a sua própria pessoa). Essa situação é favorável ao reforço da ilusão da existência de um "foro interior" ou de um "eu intimo" (autêntico) independente de toda cena social, ao mesmo tempo em que é a distância ou disjunção entre o que o social depositou em nós e aquilo que nos oferece como possibilidade de efetivação das nossas disposições e capacidades diversas neste ou naquele momento do tempo que é a origem de tal sentimento. Entretanto, inversamente, as situações de crise podem ser produzidas pelas múltiplas ocasiões de desajustamento, de cisão entre o que incorporamos e o que as situações exigem de nós.
Trata-se então de crises da relação de cumplicidade ou da conivência ontológica entre o passado tornado corpo e a nova situação. Enfim, por não possuir o dom da ubiqüidade, o indivíduo pode sofrer da multiplicidade dos investimentos sociais que se apresentam a ele e que podem acabar entrando em concorrência, quiçá em contradição.

Assim, é pela diferenciação do nosso mundo contemporâneo e por sermos portadores de disposições e capacidades (mais ou menos) plurais que nós podemos viver essas pequenas ou essas grandes preocupações, que talvez terminem por condenar nossa existência. Esses maus e mal-estares socialmente produzidos são ainda os objetos de estudo privilegiados da sociologia psicológica. 